\title{
DEVELOPMENT OF THE TOPOGRAPHICAL PROJECTION OF MOTOR NEURONS TO A RAT MUSCLE ACCOMPANIES LOSS OF POLYNEURONAL INNERVATION
}

\author{
M. R. BENNETT ${ }^{1}$ AND N. A. LAVIDIS \\ The Neurobiology Research Centre, University of Sydney, New South Wales 2006 Australia
}

Received February 15, 1983; Revised September 1, 1983; Accepted February 24, 1984

\begin{abstract}
The rat lateral gastrocnemius muscle receives a topographical projection from lumbar segmental nerves L4 and L5. A study has been made of the development of this projection during the period when polyneuronal innervation is eliminated.

The tetanic contraction due to stimulation of each nerve was compared with that due to stimulation of both nerves simultaneously. This percentage of contraction declined from about $90 \%$ to $70 \%$ for L4 from birth to 2 postnatal weeks; it declined from about $90 \%$ to $30 \%$ for L5 over the same period. The innervation of about $60 \%$ of the cells by both L4 and L5 is therefore eliminated during 2 postnatal weeks.

Tetanic and twitch contraction due to stimulation of ventral rootlets of segmental level L4 and L5 was compared to stimulation of the whole muscle directly. There was a general reduction in the size of the motor units from both L4 and L5. A selective reduction in the number of L5 motor units was observed during the first 5 postnatal days.

The distribution of L4 and L5 terminals on the dorsal surface of the muscle was determined by intracellular impalement of muscle cells and was determined by recording endplate potentials (EPPs) due to stimulation of L4 and L5. Polyneuronal innervation of the lateral gastrocnemius is eliminated by about 2 postnatal weeks. The percentage of muscle cells innervated by L4 or L5 in each of six equal-size muscle sectors was ascertained during this period. This percentage of innervation of muscle cells by L5 declined in all sectors between 3 days and 2 weeks postnatal. In one sector, L5 was entirely eliminated; there was no significant decrease in L4 innervation of any sector during this period. This loss of L5 terminals establishes a topographical projection.

The average size of EPPs evoked at segmental nerve terminals destined to regress was less than that of terminals destined to be maintained.

These observations indicate that terminals of L5 are eliminated in preference to terminals of L4 during the loss of polyneuronal innervation. This loss involves both a general decrease in size of motor units by L4 and L5 and a selective loss of L5 motor units. This establishes a topographical projection of L4 and L5 onto the lateral gastrocnemius muscle.
\end{abstract}

Both muscles and neurons are innervated by an excess number of axons during early development (Redfern, 1970; Bennett and Pettigrew, 1974, 1975; Brown et al., 1976; Mariani and Changeux, 1981; Purves, 1981; Bennett, 1983). The mechanism of elimination of this excess innervation is not known (Willshaw, 1981). In developing rat muscles some of the excess axons relocate their terminals on muscle cells which form during this period (Betz et al., 1979). Most skeletal muscles receive a topographical projection from their motor neuron pool (Sherrington 1892; Browne, 1950; Burke and Tsairis, 1973; Bennett and Raftos, 1977; Bennett and Lavidis, 1982). This topographical projection is established in developing amphibia during the period of loss of polyneuronal innervation (McGrath and Bennett, 1979; Bennett and Lavidis, 1982). It is therefore possible that the establishment of such projections is contin-

${ }^{1}$ To whom correspondence should be addressed. gent on this loss, inappropriate synaptic connections being eliminated during this period.

The present work investigates whether the development of the topographical projection of motor neurons to a rat muscle accompanies the loss of polyneuronal innervation through a selective loss of motor units.

\section{Materials and Methods}

The lateral gastrocnemius muscle of the albino rat (Wistar) was used in all experiments. Rats were anesthetized with ether and the skin was removed over the spinal cord and around the hindlimbs. A dorsal laminectomy was then performed to expose the lumbar dorsal root ganglia 4 and 5 (L4 and L5); these were dissected free, together with their accompanying dorsal and ventral roots. Spinal nerves L4 and L5 were then cleared to where they joined the sciatic nerve; this was then freed as far as the gastrocnemius muscle. The limb was then removed at its pelvic insertion and, together with the sciatic nerve and ventral roots, placed in a Perspex organ bath. This was perfused at room 
temperature with a modified Krehs solution of the following composition (mM): $\mathrm{Na}, 151 ; \mathrm{K}, 4.7 ; \mathrm{Ca}, 1.8 ; \mathrm{Mg}, 1.2 ; \mathrm{Cl}, 142 ; \mathrm{H}_{2} \mathrm{PO}_{4}, 1.3 ; \mathrm{SO}_{4}$, $1.2 ; \mathrm{HCO}_{3}, 16.3$; glucose, 7.8 . The solution was gassed continuously with $95 \% \mathrm{O}_{2}$ and $5 \% \mathrm{CO}_{2}$.

Contraction. For these studies, both the medial gastrocnemius and soleus muscles were dissected from the lateral gastrocnemius; nerves to all muscles of the leg were cut. The distal tendon of the lateral gastrocnemius was then freed and attached to a Statham tension transducer; the bone at the proximal insertion of the muscle was pinned to Sylgard at the bottom of the bath. The output of the transducer was monitored with a pen recorder. This transducer was sensitive to applied forces of less than $10 \mathrm{mg}$ and responded linearly up to $5 \mathrm{gm}$; it had a frequency response greater than $200 \mathrm{~Hz}$. The resting tension of each muscle was adjusted to give a maximal isometric twitch response. The ventral roots of $\mathrm{L} 4$ and $\mathrm{L} 5$ were stimulated with suction electrodes; square wave pulses of 1 to $5 \mathrm{~V}$ amplitude and 10 to $100 \mu \mathrm{sec}$ duration were used. Tetanic stimulation consisted of trains of impulses at $40 \mathrm{~Hz}$ for about $300 \mathrm{msec}$; this was sufficient time for a plateau to be reached in the tetanic contraction. Tetanic contraction to stimulation of both L4 and L5 was generally used to give a measure of maximum tetanic contraction. This gave the same maximum contraction as that obtained by direct muscle stimulation, when tested. Such direct stimulation was obtained by placing a suction electrode on the muscle; a small negative pressure then formed a seal between the electrode's mouth and the muscle. Pulses of $100 \mathrm{~V}$ and 5 msec duration were then applied.

The tetanic contraction due to stimulation of $\mathrm{L} 4$ and L5 was expressed as a percentage of the contraction due to stimulation of both nerves simultaneously ( $\mathrm{L} 4$ and $\mathrm{L} 5$ ). This percentage of contraction was taken as a measure of the percentage of the muscle innervated by each nerve. Tetanic contractions were used in preference to twitch contractions, as series elasticity gives rise to nonlinear summation of the twitch tensions of different motor units (Brown and Matthews, 1960).

Ventral roots were teased into filaments in order to estimate the number of motor units and their size; these teased roots were stimulated with suction electrodes. The teasing of each root was continued until individual filaments contained at most four axons to the lateral gastrocnemius; in general they contained only one axon. This was shown by grading the strength of the square wave-stimulating pulse to the filament and observing the number of increments in the amplitude of the muscle contraction (Brown et al., 1976).

Electrophysiology. For these studies, all muscles were left intact in the limb; however, the nerves to all muscles but the gastrocnemius and soleus were cut. Intracellular recordings were made with glass microcapillary electrodes which had been filled with $2 \mathrm{M} \mathrm{KCl}$ and had resistances between 40 and 80 megohms. The criteria used for determining the quality of an intracellular impalement was a resting potential of greater than $50 \mathrm{mV}$ maintained for at least $5 \mathrm{~min}$. Furthermore, in the absence of tubocurare, the mean amplitude of miniature endplate potentials (MEPPs) was not less than $0.7 \mathrm{mV}$. These criteria may have shown a bias toward recording from larger diameter muscle cells. The signals were led through a high impedance unity gain preamplifier, displayed on an oscilloscope and recorded with a tape recorder. Estimates of the quantal content of the endplate potential (EPP) at different terminals were made after the EPP was made subthreshold by increasing $[\mathrm{Mg}]_{0}$ to $10 \mathrm{mM}$. The mean quantal content of the EPP was determined from the ratio of mean EPP amplitude of at least 150 impulses to mean MEPP amplitude; in some cases, when about $30 \%$ of the impulses failed to evoke transmitter release, the method of failures was used (del Castillo and Katz, 1954). No EPPs were greater than 2 $\mathrm{mV}$ amplitude, so that corrections for nonlinear summation were not made (Martin, 1955). In some cases the EPP was made subthreshold by adding tubocurare $\left(10^{-7}\right.$ to $\left.10^{-6} \mathrm{M}\right)$ in a normal $[\mathrm{Ca}]_{0}$ and $[\mathrm{Mg}]_{0}$. Due to stimulation of L4 and L5, the amplitude of the EPPs in a cell could then be compared (see Fig. 8 ).

The segmental innervation of the lateral gastrocnemius by $\mathrm{L} 4$ and L5 was mapped by first dividing the muscle, by means of a graduated eyepiece, into six longitudinal sectors of equal width: sector 1 was immediately adjacent to the medial gastrocnemius; sector 6 was immediately adjacent to the tibialis anterior muscle. The ventral roots of L4 and L5 were stimulated in turn following impalement of a muscle cell in the endplate region. The number of nerve terminals formed by each ventral root was then estimated by gradually increasing the strength of stimulation and noting consistent changes in the amplitude of the EPP response (Bennett and Pettigrew, 1974). The impalement was then classified in terms of the sector in which it was made, by means of the graduated eyepiece.

\section{Results}

Segmental innervation: Contraction measurements. The lateral gastrocnemius is innervated by segmental nerves L4 and L5. The contraction due to tetanic stimulation of each of these nerves may give a measure of the extent of innervation by each nerve. Stimulation of these nerves at $40 \mathrm{~Hz}$ for about $500 \mathrm{msec}$ gives a maintained tetanic contraction (Fig. 1). At 12 postnatal days the sum of the contractions due to stimulation of L4 and L5 separately was the same as that due to stimulation of both nerves simultaneously (Fig. 1). However, this was not the case at earlier postnatal times: at 2 postnatal days the sum of the L4 and L5 contractions was much greater than that due to stimulation of both nerves simultaneously (Fig. 1). The contraction due to stimulation of a segmental nerve may be expressed as a percentage of the contraction due to stimulation of both nerves simultaneously. The percentage of contractions due to stimulation of L4 and L5 was determined throughout the first 2 postnatal weeks (Fig. 2). The percentage of contraction due to L4 declined only slightly from about $90 \%$ to $70 \%$. However, the percentage of contraction due to L5 declined considerably during this period: at 2 postnatal days it was $90 \%$ and by 14 days it had reached a steady value of about $30 \%$ (Fig. 2 ). The addition of the individual percentages of contraction therefore summed to over $100 \%$ until 14 postnatal days (Fig. 2 ). These results suggest that most muscle cells are innervated by both L4 and L5 in the early postnatal period.

Estimates of the number and size of motor units in each of segmental nerves L4 and L5 were also made. Figure 3 shows that the motor units in each nerve are generally large at birth; they then decline and reach their mature size by about 10

\section{GASTROCNEMIUS}

2day

12 day
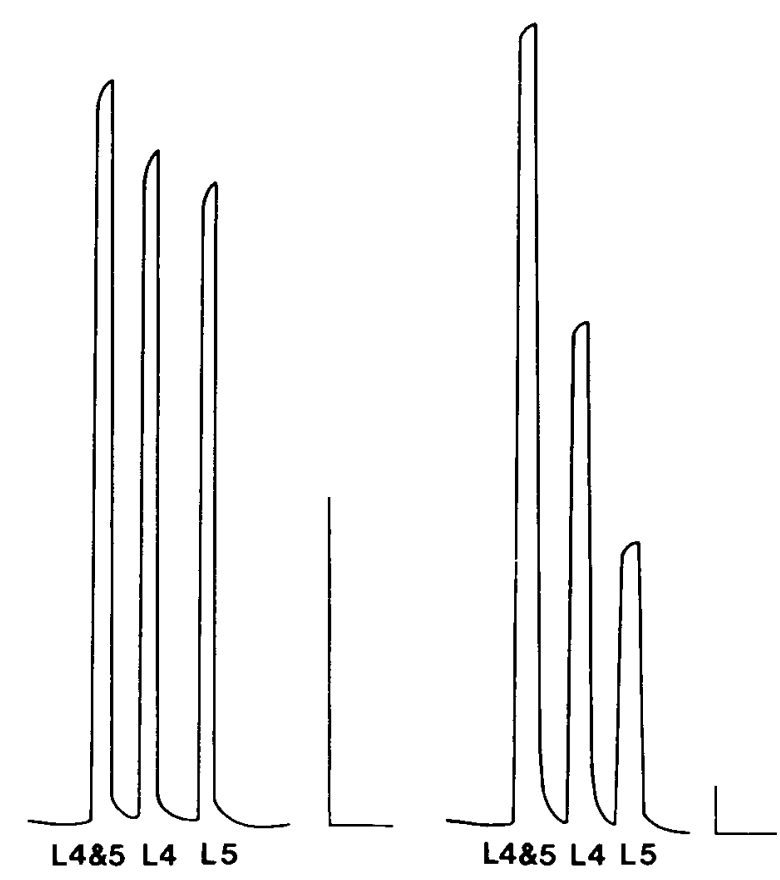

Figure 1. Tetanic construction of 2-day and 12-day lateral gastrocnemius muscles to stimulation of either lumbar nerve $4(L 4)$ or $5(L 5)$ or both nerves ( $L A \& 5$ ). Calibrations are $2 \mathrm{gm}, 1 \mathrm{sec}$. 


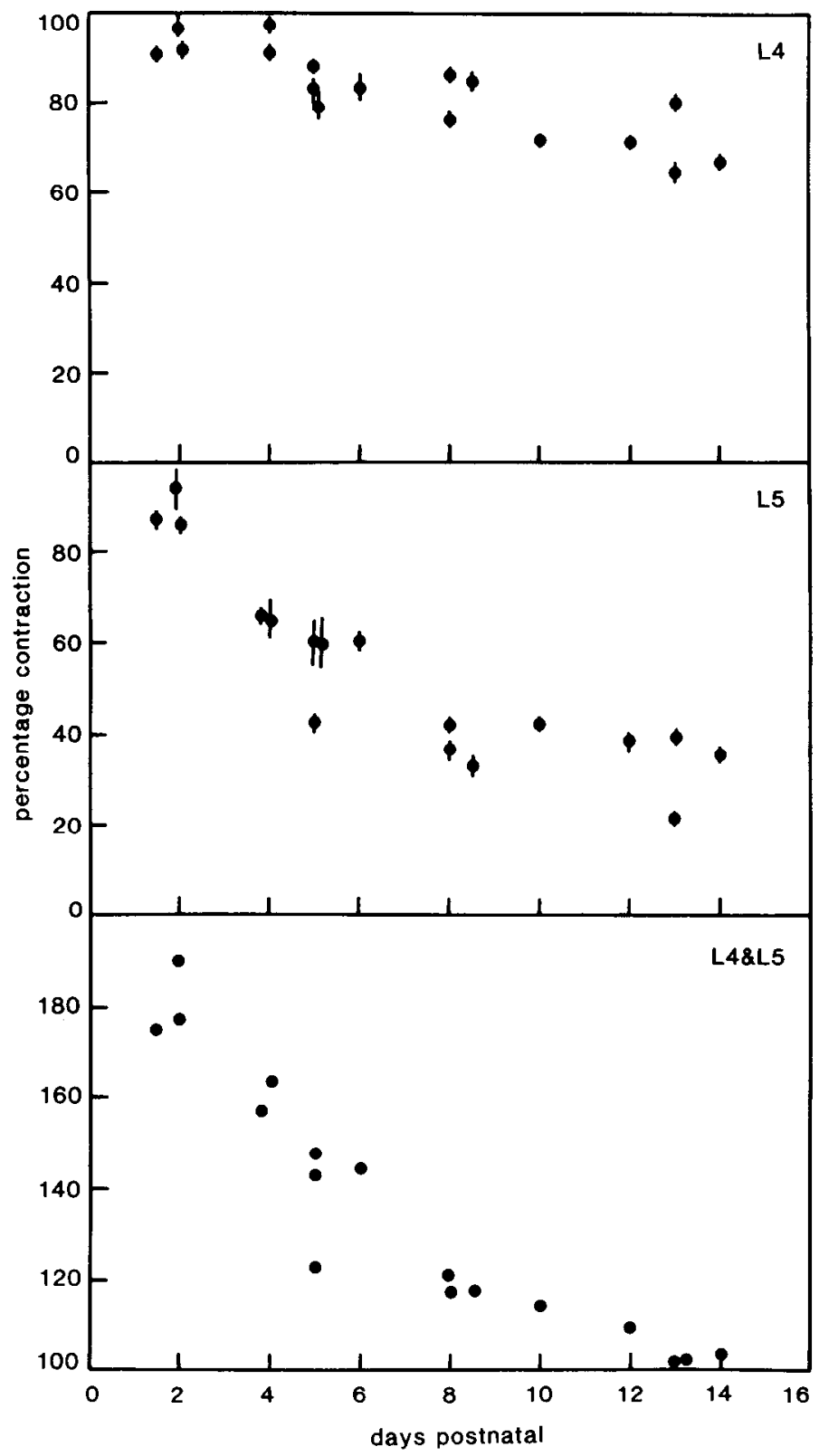

Figure 2. Size of the tetanic contractions of the lateral gastrocnemius produced by stimulating $\mathrm{L} 4$ or $\mathrm{L} 5$ ventral roots. The results are expressed as a percentage of the contraction due to stimulation of both nerves simultaneously. $L A \& L 5$ refers to the addition of the percentage of contraction due to stimulating L4 and L5 independently; this should be $100 \%$ if there is no overlap in the innervation of muscle cells by the segmental nerves. Each point gives the mean \pm SEM of at least six tetanic contraction measurements for one lateral gastrocnemius muscle from a rat at the age given on the abscissa.

postnatal days. The number of motor units in L4 remains approximately constant at about 15 throughout the postnatal period (Fig. 4). However, the number of motor units in L5 is not constant; it declines during the first 2 postnatal weeks (Fig. 4). There was a 2-fold difference in the number of L5 motor units between less than 2 days and more than 10 days postnatal. This difference was significant since using the Student's $t$ test $(p<0.05)$.

Segmental innervation: Electrical measurements. Next an attempt was made to obtain electrophysiological evidence for the innervation of muscle cells by both L4 and L5. In addition, the distribution of L4 and L5 terminals over the surface of the

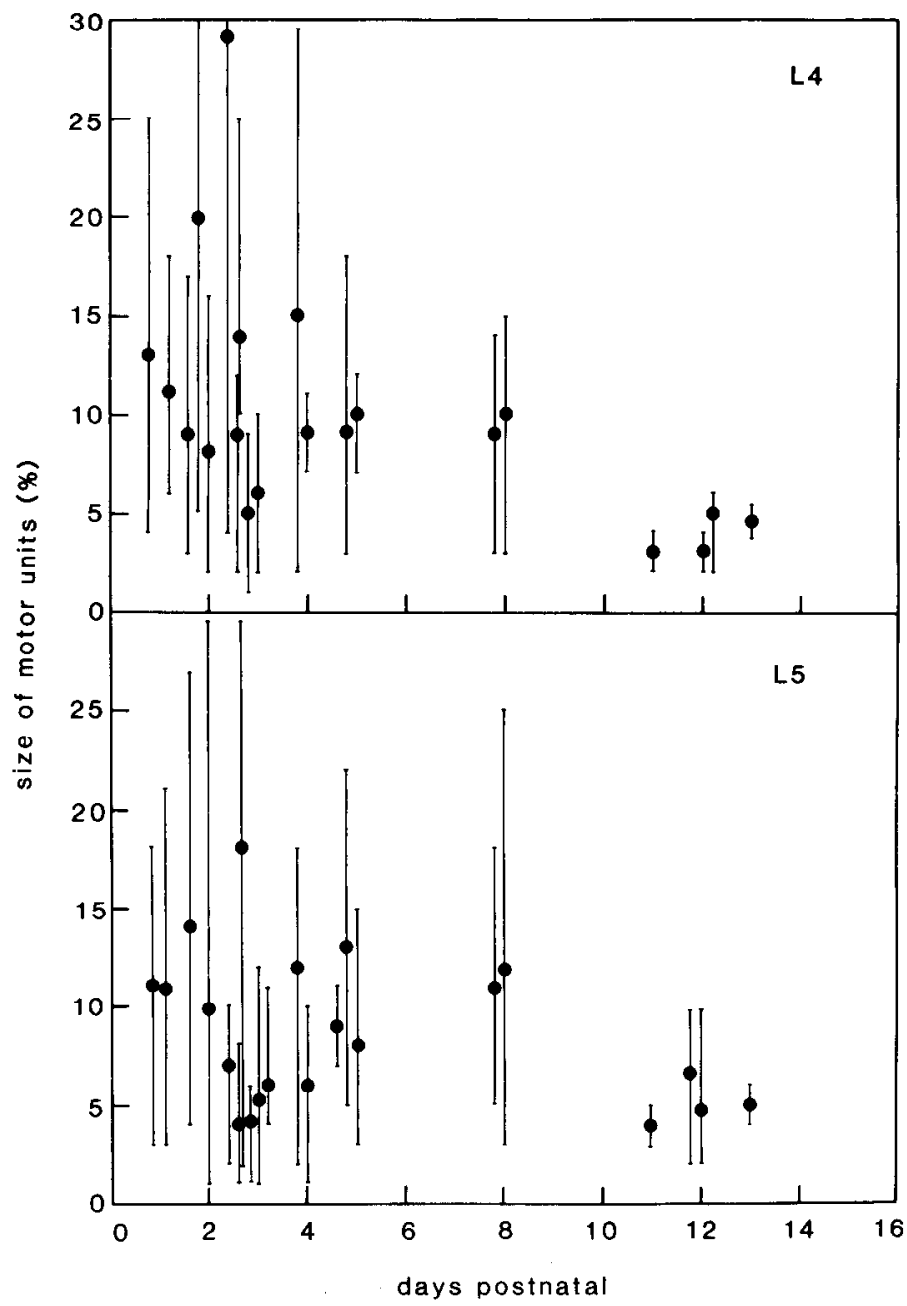

Figure 3. Size of motor units in L4 and L5 to the lateral gastrocnemius at different ages. Each vertical line gives the observations on one muscle. The ordinate gives the size of motor units expressed as a percentage of the maximum tetanus to direct stimulation of the muscle The vertical lines give the range of individual measurements for the lowest threshold motor unit in the ventral root filaments; the solid circles give the mean size of the motor units.

lateral gastrocnemius at different postnatal times was determined. To this end the dorsal surface of the muscle was divided into six sectors of equal size by means of a calibrated eyepiece: sector I was immediately adjacent to the medial gastrocnemius; sector 6 apposed the tibialis anterior. At least eight muscle cells were impaled in each sector and EPPs due to stimulation of L4 and L5 were ascertained. The innervation of each sector by L4 or L5 changed during development. For example, EPPs could be evoked in many cells of sector 6 on stimulation of both L4 and L5 during the first postnatal week (Fig. 5); by 2 weeks, EPPs could only be evoked in this sector on stimulation of L4 (Fig. 5). In preparations younger than 3 days, slow time course EPPs were recorded in some cells in addition to the normal fast time course EPPs. These slow EPPs are probably due to EPPs generated in adjacent cells and conducting into the impaled cell through electrical couplings between muscle cells in a cluster (Dennis et al., 1981; Schmalbruch, 1982); these slow EPPs were discounted. The percentage of cells in each sector which gave an FPP on stimulation of I 4 or I.5 was obtained at different postnatal times. Examples of the percentage of innervation of each sector determined in this way are shown in Figure 6. Most cells are innervated by both nerves in each 


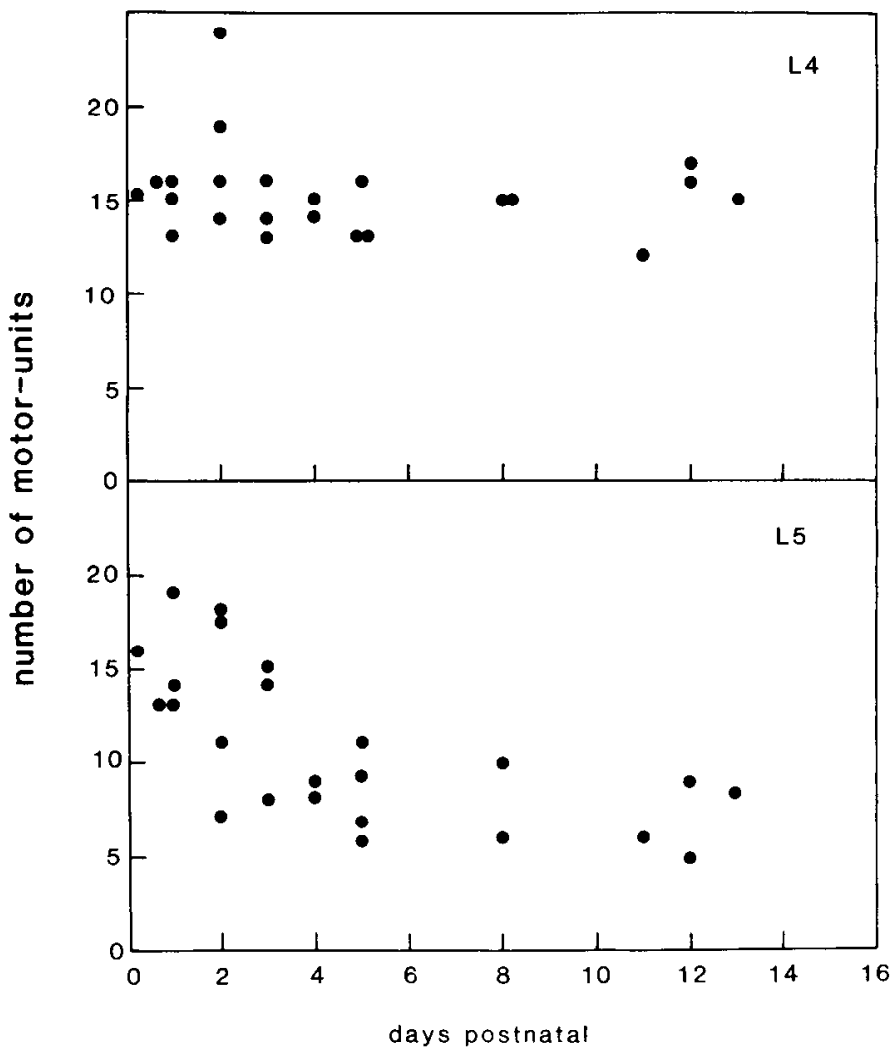

Figure 4. Number of motor units in L4 and L5 to the lateral gastrocnemius at different ages. Each solid circle gives the results for a single muscle.

sector at 3 postnatal days. There is then a decline in the percentage of innervation of each sector by L5; L5 no longer innervates sector 6 by the end of the second week and provides very little innervation of sector 5 (Fig. 6). Table I summarizes the changes in percentage of innervation of each muscle sector between 3 and 5 postnatal days: the significant changes are a decrease in L5 innervation of all sectors and an increase in innervation of sector 6 by L4. This decline in the innervation of sectors by L5 is accompanied by decline in the polyneuronal innervation of muscle cells (Fig. 7); part of this is due to the removal of synapses formed by L5 terminals.

It is possible to make a quantitative comparison between the contractile and electrical estimates of the percentage innervation by $\mathrm{L} 4$ and $\mathrm{L} 5$. This requires an assumption-namely, that the percentage of innervation of a sector determined from the impalement of cells at the surface of a muscle is true for cells lying deep within the sector. If this is true, then the mean of the percentages of innervation in each sector of a muscle by a segmental nerve should be equal to the percentage of the muscle innervated by that nerve. The percentage of innervation by L4 and L5 of each muscle for which an electrophysiological study was made has been determined (Fig. 8): L4 remains constant at about $80 \%$, whereas L5 declines from $80 \%$ to about $30 \%$ by 12 postnatal days. The contraction and electrical measurements give about the same rate of decline for the percentage of innervation by L5 (compare Fig. 8 with Fig. 2).

Synaptic transmission of segmental nerve terminals. A comparison was made of the average quantal content of the EPP recorded in different sectors on stimulation of L4 or L5. The magnesium concentration was increased to $10 \mathrm{mM}$ in order to make the EPP subthreshold for initiation of an action potential. When the average quantal content of the EPPs evoked by stimulation of L5 was determined in the first postnatal week,
4 day
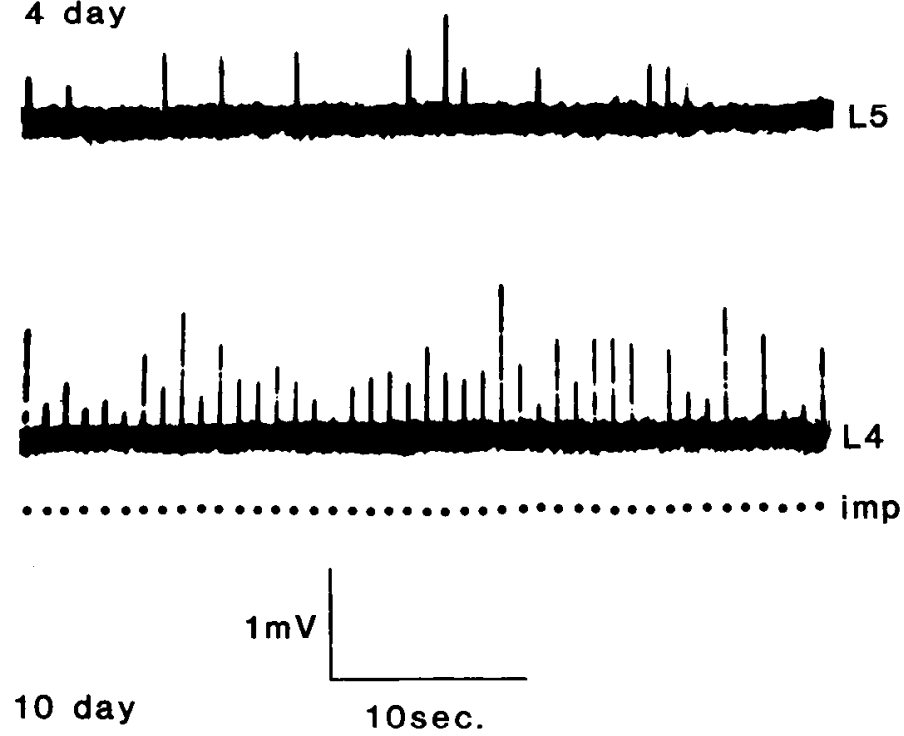

$\mathbf{L} 5$

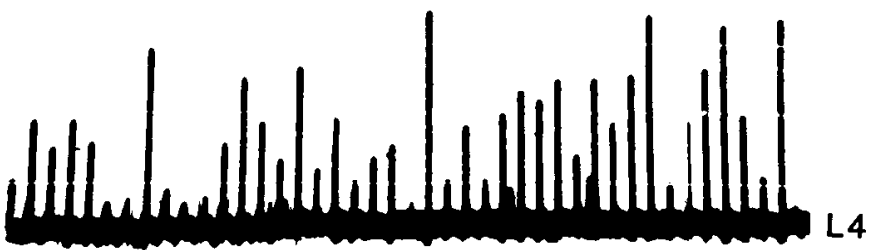

Figure 5. EPPs recorded in muscle cells of sector 6 in the lateral gastrocnemius (next to the tibialis anterior) at 4 days and 10 days postnatal. The frequency of stimulation indicated (imp) is $1 \mathrm{~Hz}$. At 4 days, stimulation of L5 gives mostly failures, with an occasional EPP; stimulation of L4 to the same cell gives mostly EPPs, with an occasional failure. At 10 days, stimulation of L5 does not evoke an EPP in a cell which gives EPPs in response to stimulation of L4.

it was always smaller in sector 6 than in sectors 1 to $3(1.0 \pm$ 0.2 (SEM) in sector 6 versus $2.7 \pm 0.3$ in sectors 1 to 3 ). During this period, the average quantal content of EPPs due to L4 stimulation was about the same in all sectors $(2.7 \pm 0.2)$. It is possible that transmission at low quantal content terminals is completely suppressed in high magnesium concentrations. In order to avoid this possibility, the EPPs were made subthreshold by adding tubocurare. The ratios of the EPP amplitudes recorded in cells following stimulation of L5 and L4 were then determined (Fig. 9, top): this ratio was significantly smaller in sector 6 than in sectors 1 to 4 . The ratio of the average EPP amplitudes to stimulation of L5 and L4 was the same in sectors 1 to 5 during the second postnatal week (Fig. 9, bottom).

Both segmental nerves innervate about the same number of cells in sectors 5 and 6 in the first few postnatal days (Table I). However, the quantal content of the EPP at L5 terminals is much lower than that of L4 terminals in these sectors at this time (Fig. 9). If the low quantal content terminals fail to transmit a nerve impulse in normal calcium and magnesium concentrations, then they will not contribute to a twitch contraction; however, they may contribute during a tetanus because of the enhancement of quantal content due to facilitation. To test this, a comparison has been made between the percentage of contractions due to L4 and L5 stimulation with trains and those with single impulses. There is a $20 \%$ decline in percentage of innervation by $\mathrm{L} 5$ between early and late postnatal periods 


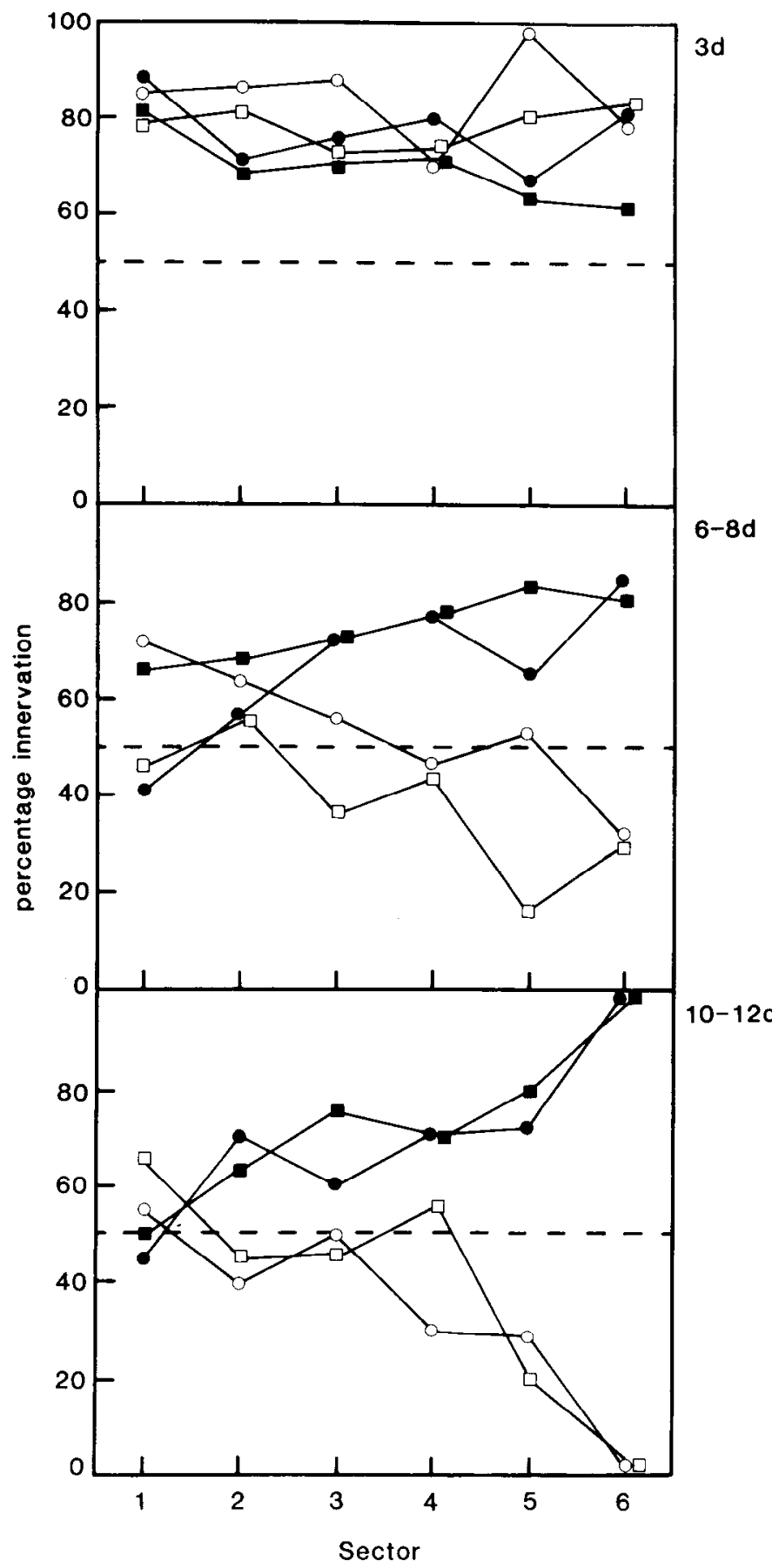

Figure 6. Percentage of muscle cells in different sectors of the developing lateral gastrocnemius innervated by L4 (solid symbols) or L5 (open symbols). Results are shown for two preparations (circles and squares) in each age group. At 3 days there is extensive polyneuronal innervation in most sectors due to innervation of muscle cells by both segmental nerves; by 10 to 12 days most of the polyneuronal innervation is eliminated, and sector 6 is only innervated by L4. The mature topographical projection of L4 and L5 is now established.

as determined by the twitch tensions (Fig. 10); this may be compared with a $55 \%$ decline determined with tetanus (Fig. 10). These results are consistent with the idea that the low quantal content terminals do not contribute to the twitch tension: there is not much difference between the percentages of contraction due to L5 measured with a twitch at early and late postnatal times (Fig. 10).

\section{Discussion}

The decrease in percentage of innervation of the lateral gastrocnemius by segmental nerve L5 from the area closest to the anterior tibialis muscle suggests that its synaptic connections are eliminated in favor of those formed by segmental nerve L4. Following this selective elimination, a topographical projection into the muscle emerges. Similar preferential elimination has been claimed to occur between L4 and L5 nerve terminals for synaptic connections in the soleus muscle; L4 terminals are eliminated in preference to L5 terminals (Miyata and Yoshioka, 1980).

One possible explanation for this result is that L4 axons initially form larger motor units than do L5 terminals: it is known that the terminals of axons forming larger motor units are at a disadvantage in competition for synaptic sites with the terminals of axons forming smaller motor units (Brown and Ironton, 1978; Wigston, 1980). However, recently it was shown in the soleus muscle of the rat (Gordon and Van Essen, 1983; Thompson, 1983) and the rabbit (Gordon and Van Essen, 1983) that the motor unit sizes of L4 and L5 are the same during the postnatal period, and they decline by the same proportional amount. Since there are fewer axons of L4 compared with L5, a larger part of the muscle is left uninnervated by L4. This suggestion can explain the nontopographical projection from segmental nerves L4 and L5 in the rat soleus muscle. A similar suggestion may be made with respect to the decline in the percentage of contraction of the lateral gastrocnemius by L5: there are only half as many L5 axons in the mature muscle, and as the motor unit sizes decline by the same proportion, a larger part of the muscle is left uninnervated by L 5 terminals. However, the establishment of a topographical projection would require the assumption that motor axons are positioned in specific areas of the lateral gastrocnemius muscle. Alternatively, muscle fibers may be selective for terminals arising from motor axons in a particular segmental level.

Another possible explanation involves the increase in muscle fibers. The number of muscle fibers in the lateral gastrocnemius increases from about 4500 at birth to 9000 by 10 postnatal days (M. R. Bennett, personal observation). It is possible that L4 alone forms synaptic connections on these newly formed muscle cells; this would decrease the percentage of innervation of the muscle by L5, without changing existing L5 synaptic connections. Muscle cells are grouped into clusters during the early postnatal period (Ontell and Dunn, 1978). Each cluster consists of a relatively mature multinucleate muscle cell, together with myotubes and satellite cells; all of these are ensheathed by a single basement membrane (Ontell, 1977). New myofibers arise within these clusters throughout the muscle present at birth (Harris, 1981); it is unlikely that new clusters are formed after birth. Each muscle sector then should increase in the same proportion according to this arrangement. As the muscle approximately doubles its complement of muscle cells in the 2 postnatal weeks, the number of cells in each sector should double. This increase is insufficient to account for the changes in percentage innervation on the basis that new cells are alone innervated by L4: the electrophysiological observation indicates that L5 is entirely eliminated from sector 6 and suffers a 6 -fold decrease in sector 5 (Table I). Experiments will have to be performed to determine the number of newly formed fibers during different stages of development in each sector.

The results indicate that the synaptic sites in the lateral gastrocnemius possess a selective preference for the terminals of L4 motor neurons during development. During the neonatal period L5 terminals are found in sectors not innervated by L5 after 9 postnatal days. Such terminals are considered to be inappropriate since they are functionally eliminated during development. The loss of polyneuronal innervation then in- 
TABLE I

Summary of observations on the percentage of muscle cells innervated in different sectors of the lateral gastrocnemius by L4 and L5 at early ( 3 to 5 days) and late (10 to 12 days) postnatal times

The mean percentage of innervation ( \pm SD) for each age group is given. Significant decreases in the innervation of sectors 1 to 6 by L5 between 3 and 5 days and between 10 and 12 days are indicated. This large decrease in L5 innervation is confirmed by the contraction studies.

\begin{tabular}{|c|c|c|c|c|c|c|c|}
\hline \multirow{2}{*}{ Time Postnatal } & \multirow{2}{*}{ Nerve } & \multicolumn{6}{|c|}{ Sector } \\
\hline & & 1 & 2 & 3 & 4 & 5 & 6 \\
\hline \multicolumn{8}{|l|}{ 3-5 Days } \\
\hline \multirow[t]{2}{*}{1} & L4 & 80 & 66 & 75 & 75 & 64 & 59 \\
\hline & L5 & 80 & 83 & 73 & 73 & 81 & 83 \\
\hline \multirow[t]{2}{*}{2} & L4 & 87 & 72 & 75 & 80 & 67 & 80 \\
\hline & L5 & 83 & 86 & 88 & 70 & 98 & 78 \\
\hline \multirow[t]{2}{*}{3} & L4 & 60 & 75 & 57 & 83 & 66 & 64 \\
\hline & L5 & 89 & 63 & 86 & 67 & 83 & 82 \\
\hline \multirow[t]{2}{*}{4} & $\mathrm{~L} 4$ & 67 & 75 & 71 & 86 & 80 & 82 \\
\hline & L5 & 75 & 75 & 86 & 70 & 70 & 64 \\
\hline \multirow[t]{2}{*}{5} & $\mathrm{~L} 4$ & 63 & 73 & 78 & 82 & 75 & 69 \\
\hline & L5 & 73 & 64 & 56 & 64 & 58 & 69 \\
\hline \multirow[t]{2}{*}{ Mean \pm SD } & L4 & $71 \pm 12$ & $72 \pm 4$ & $71 \pm 4$ & $81 \pm 2$ & $70 \pm 7$ & $71 \pm 10^{a}$ \\
\hline & L5 & $83 \pm 3^{a}$ & $74 \pm 11^{a}$ & $78 \pm 14^{a}$ & $69 \pm 2^{a}$ & $78 \pm 7^{a}$ & $75 \pm 8^{a}$ \\
\hline \multicolumn{8}{|l|}{$10-12$ days } \\
\hline \multirow[t]{2}{*}{1} & $\mathrm{~L} 4$ & 72 & 84 & 80 & 66 & 100 & 100 \\
\hline & $\mathrm{L} 5$ & 50 & 46 & 40 & 50 & 0 & 0 \\
\hline \multirow[t]{2}{*}{2} & $\mathrm{~L} 4$ & 50 & 63 & 77 & 71 & 80 & 100 \\
\hline & L5 & 67 & 45 & 46 & 56 & 20 & 8 \\
\hline \multirow[t]{2}{*}{3} & $\mathrm{~L} 4$ & 45 & 70 & 60 & 70 & 70 & 100 \\
\hline & L5 & 55 & 40 & 50 & 30 & 30 & 0 \\
\hline \multirow[t]{2}{*}{4} & $\mathrm{~L} 4$ & 63 & 50 & 73 & 78 & 100 & 100 \\
\hline & L5 & 36 & 57 & 27 & 22 & 0 & 0 \\
\hline \multirow{2}{*}{ Mean $\pm \mathrm{SD}$} & $\mathrm{L} 4$ & $58 \pm 6$ & $67 \pm 14$ & $73 \pm 9$ & $71 \pm 5$ & $88 \pm 15$ & $100 \pm 0$ \\
\hline & L5 & $52 \pm 13$ & $47 \pm 7$ & $41 \pm 10$ & $40 \pm 16$ & $13 \pm 15$ & $0 \pm 0$ \\
\hline
\end{tabular}

${ }^{a} p<0.01$ by the Student's $t$ test.

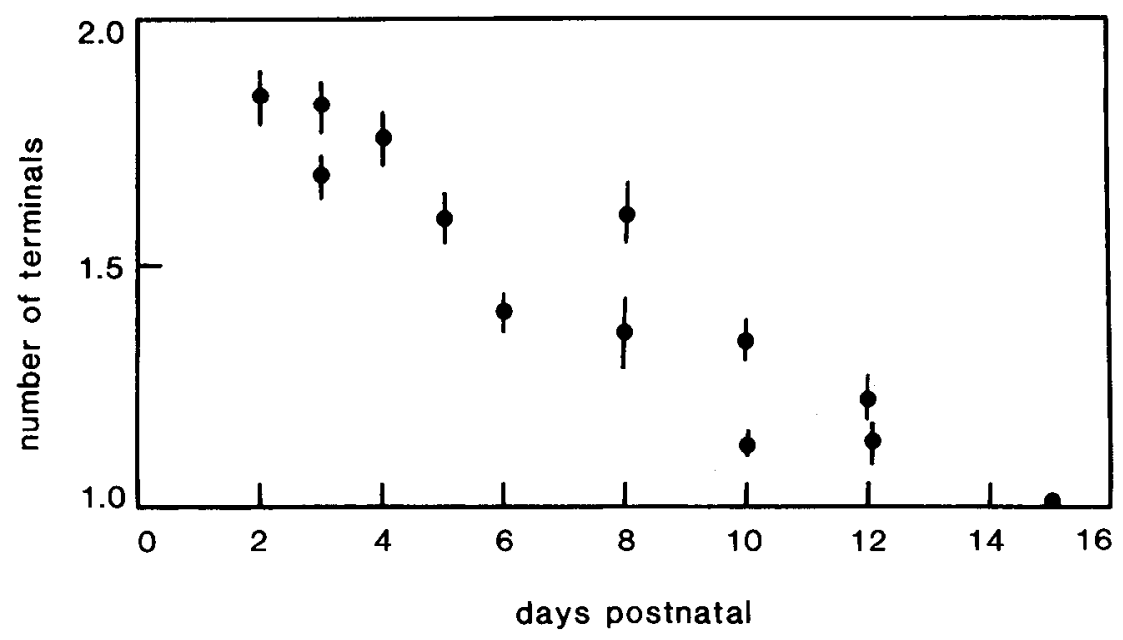

Figure 7. Changes in the number of terminals at synaptic sites in the lateral gastrocnemius during postnatal development. Each point gives the mean $( \pm \mathrm{SEM})$ number of terminals estimated from at least 50 synaptic sites in a single preparation.

volves the selective elimination of L5 terminals; this establishes a topographical projection from the appropriate segmental nerves to the muscle. A similar process has been observed in axolotl muscle; inappropriate connections are first established in the flexor muscle comprising the musculus pubotibialis and musculus pubo-ischiotibialis (Fig. 1 in McGrath and Bennett, 1979). During early development, nerves 16 and 17 innervate the muscle surface equally. At maturity terminals from nerve 17, previously found in sectors 3 and 4 (see Fig. 2 in McGrath and Bennett, 1979), are eliminated from this region. The loss of such inappropriate terminals leads to the establishment of the topographical projection by nerves 16 and 17 on the axolotl flexor muscle. Such inappropriate segmental nerve projections have also been shown to occur in the frog glutaeus muscle (Bennett and Lavidis, 1982). In mature frogs only nerve 9 terminals are recorded from the muscle fibers of the glutaeus muscle in the region closest to the iliofibularis muscle, whereas in the early stages of development both nerves 8 and 9 are 


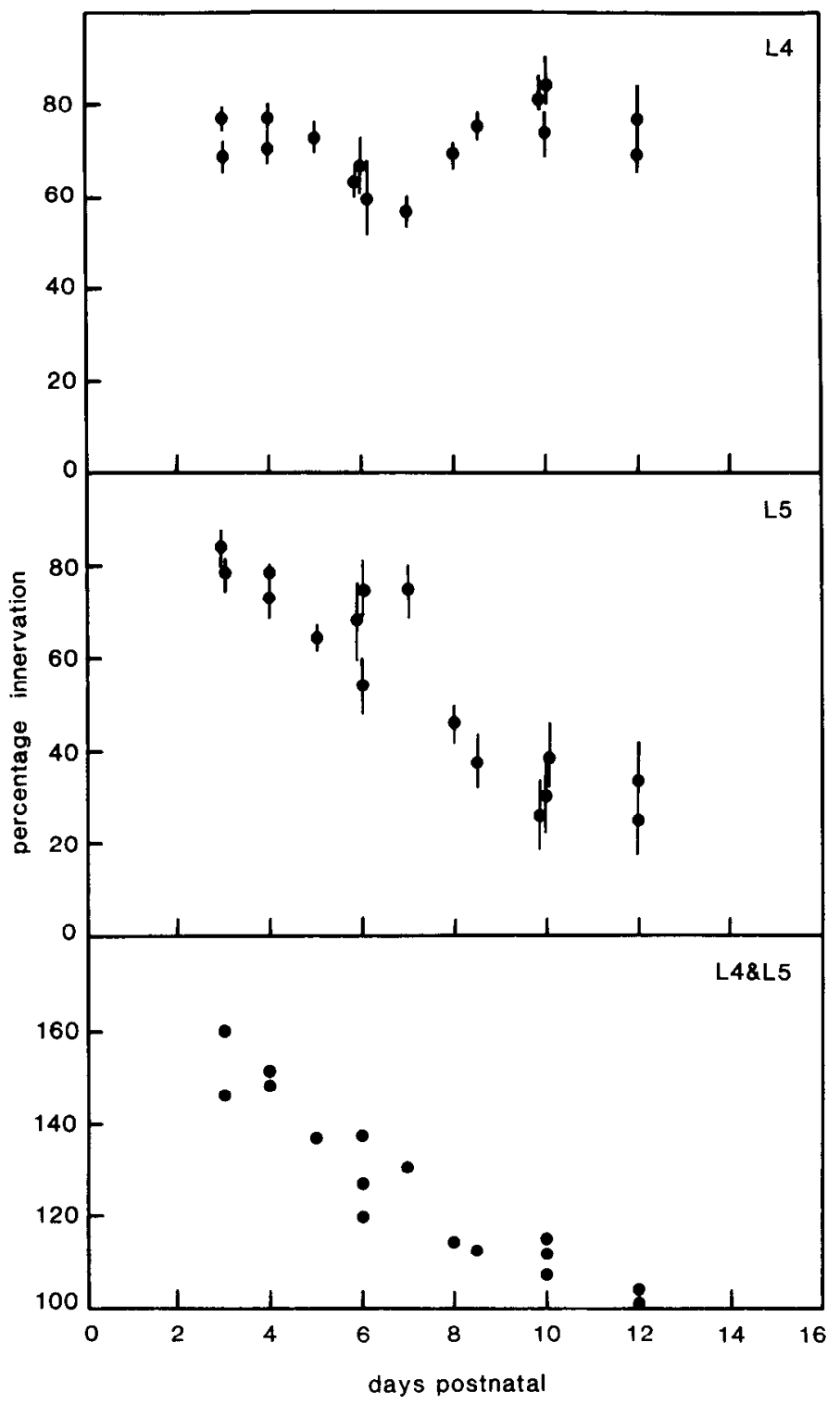

Figure 8. Comparison of the extent of lateral gastrocnemius innervated by $\mathrm{L} 4$ and $\mathrm{L} 5$ during development, determined from electrophysiological studies. The percentage of muscle cells innervated by either segmental nerve has been determined from the average of the percentages of innervation of each sector (see Table I and Fig. 6). The percentage of innervation by $\mathrm{L} 4$ and $\mathrm{L} 5$ determined by this method changes during the postnatal period in manner similar to that determined by the contraction methods (cf. Fig. 2). The mean percentage of innervation by L4 and L5 is given together with the SEM.

present equally. The preferential loss of nerve 8 terminals from this area leads to the establishment of the topographical projection. In this work on axolotl and frog muscles and in the present study it is shown that inappropriate connections are first established during early development of the projection from appropriate segmental nerves to a muscle. Regression of these connections then establishes a topographical projection. Similar results have been presented by Brown and Booth (1983) for the rat glutaeus muscle.

Adult axolotl muscle cells possess synaptic sites which can distinguish between foreign and native nerves (Holder et al., 1982); during competition between these nerves for synaptic sites, the foreign terminals regress in favor of the native terminals (Dennis and Yip, 1978; Bennett et al., 1979). The quantal content of the EPP in such foreign terminals is sub-

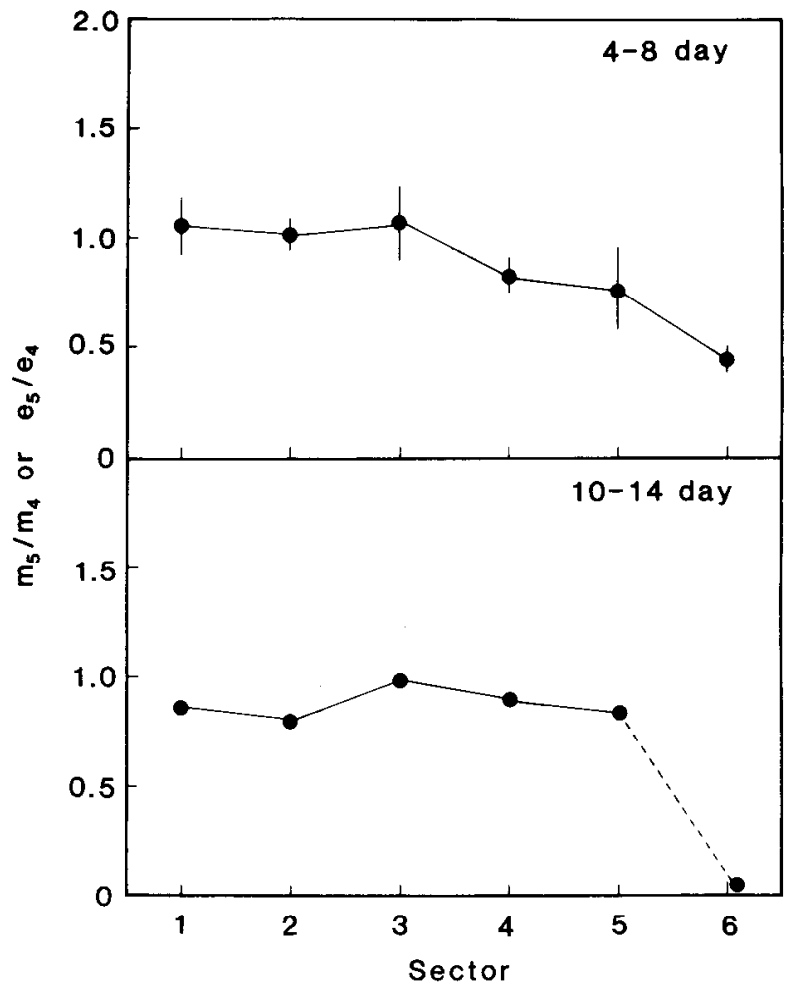

Figure 9. The ratio of EPP amplitudes in each sector due to stimulation of L5 and L4. Top, First postnatal week. The ratio of EPP amplitudes to L5 and L4 stimulation were determined for cells innervated by both segmental nerves; the average of these ratios is shown for eight preparations ( \pm SEM). Bottom, End of second postnatal week. The EPP amplitudes to L5 and L4 stimulation were determined for different cells in a given preparation, and the ratio of these amplitudes was estimated for each sector; the averages of these ratios over eight preparations are shown. There was no significant difference between the ratios of L5 to L4 EPP amplitudes and the ratios of L5 to L4 quantal contents estimated for each sector. No L5 EPPs were observed in sector 6 at about 2 weeks postnatal.

stantially lower than that at mature terminals (Holder et al., 1982); a similar result was obtained in the present work for L5 terminals in sector 6 , from which they are destined to be eliminated (Fig. 7). If the segmental nerves to an axolotl muscle are cut, the topographical projection onto the muscle is reestablished on reinnervation; this follows a transient period in which inappropriate connections are formed and then eliminated (Cass and Mark, 1975; Bennett and McGrath, 1980). This experiment may mimic the events which occur during normal development: appropriate and inappropriate connections are made with muscle fibers so that most of the muscle fibers are polyneuronally innervated; the inappropriate connections show lower quantal contents and are unstable; such connections are eliminated if an appropriate terminal exists on the muscle fiber. The synaptic sites on mature mammalian and frog muscles can distinguish between preganglionic and motor axons (Landmesser, 1972; Bennett et al., 1973; Grinnell et al., 1979). Furthermore, the synaptic sites in mature rat intercostal muscles possess a selective preference for the preganglionic terminals from different segmental levels of the thoracic outflow (Wigston and Sanes, 1982); more rostral intercostal muscles are preferentially innervated by more rostral preganglionic axons. This selective property of synaptic sites for preganglionic axons from different segmental levels may also act to distinguish between motor axons from different segmental levels (L4 and L5) during the development of topographical projection to the lateral gastrocnemius muscle of the rat. 


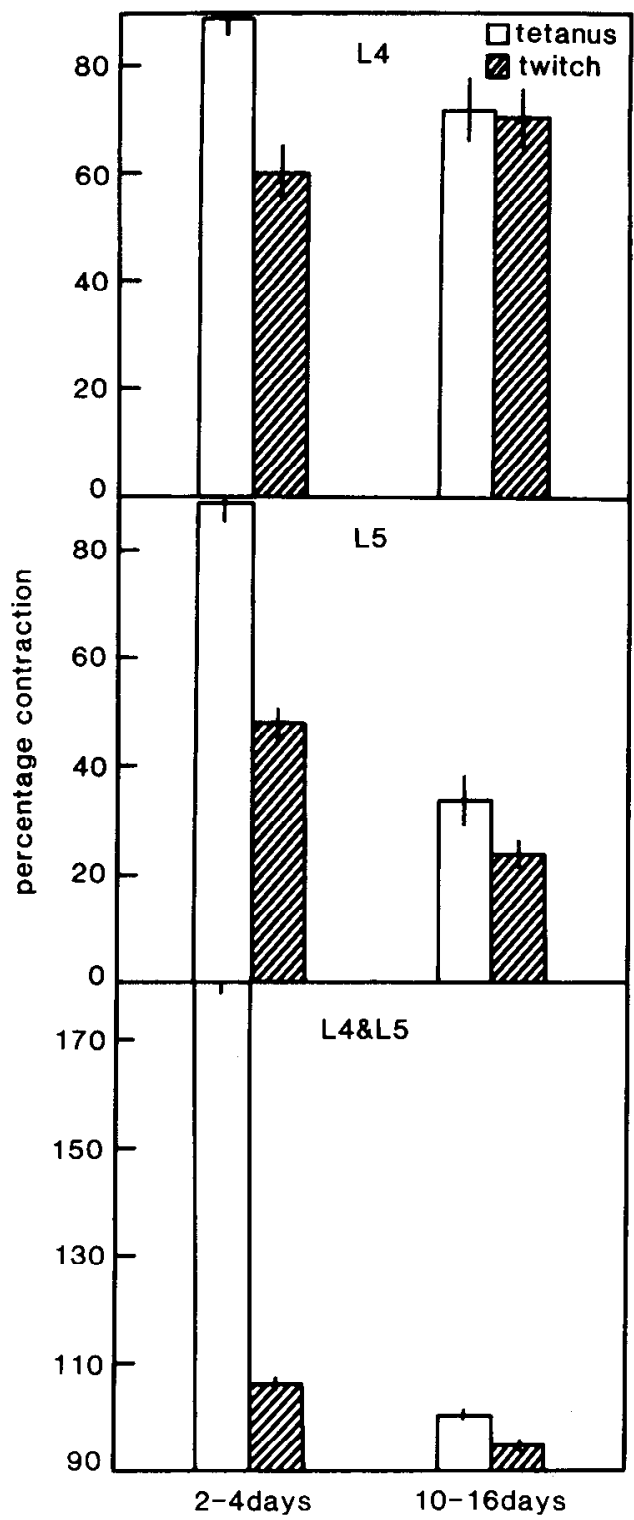

Figure 10. Comparison between the percentage of innervation of the lateral gastrocnemius by L4 and L5 as determined by tetanic contraction measurements (open histogram bars) and those determined hy twitch contraction measurements (hatched histogram bars). The twitch measurements indicate no decline in the innervation by L4 between early ( 2 to 4 days) and late ( 10 to 16 days) postnatal periods. However, these measurements show a significant decline in the innervation by L5. This decline is relatively small compared with that indicated by the tetanic contraction measurements. The histugram bars give the means $\pm \mathrm{SEM}$ of at least four measurements.

The fate of the motor units with low quantal content terminals which are eliminated from synaptic sites is still unclear. Most of the motor units remain functionally present on the muscle while they decrease their field of influence; a few are totally eliminated. The number of motor units in L5 preferentially declined during the first postnatal week in the lateral gastrocnemius muscle; this estimation was based on the method of dividing ventral roots into four or five rootlets, grading the strength of the stimulus to the filaments of the L5 ventral root, and observing the number of increments in amplitude of the muscle twitch. The results suggest that motor neuron death may occur in L5 units supplying the lateral gastrocnemius muscle during the postnatal period; alternatively, the axons terminals may become nonfunctional. In order to make a dis- tinction between these possibilities, direct counts of motor neurons are required. Such counts have been made in the brachial level of the lateral motor column. More than $40 \%$ of the motor neurons in the brachial level of the lateral motor column degenerate in the rat during the first postnatal week (Nurcombe et al., 1981).

The intracellular recordings and tension studies made in the present work suggest that the topographical projection of segmental nerves L4 and L5 onto the lateral gastrocnemius muscle emerges during the loss of polyneuronal innervation. This loss occurs as a result of both a selective decrease in the number of motor units from one segmental level during the first 5 postnatal days and a general decrease in the size of motor units lasting 9 postnatal days.

\section{References}

Bennett, M. R. (1983) Development of neuromuscular synapses. Physiol. Rev. 63: 915-1049.

Bennett, M. R., and N. A. Lavidis (1982) Development of the topographical projection of motor neurons to an amphibian muscle accompanies motor neuron death. Dev. Brain Res. 2: 448-452.

Bennett, M. R., and P. A. McGrath (1980) Segmental innervation of rotated and supernumerary axolotl hindlimbs. J. Exp. Zool. 214: 112.

Bennett, M. R., and A. G. Pettigrew (1974) The formation of synapses in striated muscle during development. J. Physiol. (Lond.) 241: 515545 .

Bennett, M. R., and A. G. Pettigrew (1975) The formation of synapses in amphibian striated muscle during development. J. Physiol. (Lond.) 252: 203-239.

Bennett, M. R., and J. Raftos (1977) The formation and regression of synapses during the reinnervation of axolotl striated muscles. J. Physiol. (Lond.) 265: 261295.

Bennett, M. R., E. McLachlan, and R. Taylor (1973) The formation of synapses in mammalian striated muscle reinnervated with autonomic preganglionic nerves. J. Physiol. (Lond.) 233: 501-518.

Bennett, M. R., P. A. McGrath, and D. F. Davey (1979) The regression of synapses formed by a foreign nerve in a mature axolotl striated muscle. Brain Res. 173: 451-469.

Bennett, M. R., P. A. McGrath, D. Davey, and I. Hutchinson (1983) Death of motor neurons during the postnatal loss of polyneuronal innervation of rat muscles. J. Comp. Neurol. 218: 351-363.

Betz, W. J., J. H. Caldwell, and R. R. Ribchester (1979) The size of motor units during postnatal development of rat lumbrical muscle. J. Physiol. (Lond.) 297: 463-478.

Betz, W. J., J. H. Caldwell, and R. R. Ribchester (1980) The effects of partial denervation at birth on the development of muscle fibres and motor units in rat lumbrical muscle. J. Physiol. (Lond.) 303: 265279.

Brown, M. C., and C. M. Booth (1983) Postnatal development of the adult pattern of motor axon distribution in rat muscle. Nature 304 : 741-742.

Brown, M. C., and R. Ironton (1978) Sprouting and regression of neuromuscular synapses in partially denervated mammalian muscles. J. Physiol. (Lond.) 278: 325-348.

Brown, M. C., and P. B. C. Matthews (1960) An investigation into the possible existence of polyneuronal innervation of individual skeletal muscle fibres in certain hind-limb muscles of the cat. J. Physiol. (Lond.) 151: 436-457.

Brown, M. C., J. K. S. Jansen, and D. Van Essen (1976) Polyneuronal innervation of skeletal muscle in new-born rats and its elimination during maturation. J. Physiol. (Lond.) 261: 387-422.

Browne, K. M. (1950) The spatial distribution of segmental nerves to striate musculature of the hindlimb of the rat. J. Comp. Neurol. 93: $441-455$.

Burke, R. E., and P. Tsairis (1973) Anatomy and innervation ratios in motor units of cat gastrocnemius. J. Physiol. (Lond.) 234: 749-765.

Cass, D. T., and R. F. Mark (1975) Reinnervation of axolotl limbs. I. Motor nerves. Proc. R. Soc. Lond. Biol. 190: 45-58.

del Castillo, J., and B. Katz (1954) Quantal components of the endplate potential. J. Physiol. (Lond.) 124: 560-573.

Dennis, M. J., and J. W. Yip (1978) Formation and elimination of foreign synapses on adult salamander muscle. J. Physiol. (Lond.) 274: $299-310$. 
Dennis, M. J., L. Ziskind-Conhaim, and A. J. Harris (1981) Development of neuromuscular junction in rat embryos. Dev. Biol. 81: 266279.

Gordon, H., and P. C. Van Essen (1983) The relation of neuromuscular synapse elimination to spinal position of rabbit and rat soleus motoneurones. J. Physiol. (Lond.) 339: 591-597.

Grinnell, A. D., M. S. Letinsky, and M. B. Rheuben (1979) Competition interaction between foreign nerves innervating frog skeletal muscle. J. Physiol. (Lond.) 289: 241-262.

Harris, A. J. (1981) Embryonic growth and innervation of rat skeletal muscle. I. Neural regulation of muscle fibre numbers. Proc. R. Soc. Lnd. Biol. 293: 257-276.

Holder, N., J. Mills, and D. A. Tonge (1982) Selective reinnervation of skeletal muscle in the newt Triturus cristatus. J. Physiol. (Lond.) 326: 371-384.

Landmesser, L. (1972) Pharmacological properties, cholinesterase activity and anatomy of nerve-muscle junctions in vagus-innervated frog sartorius. J. Physiol. (Lond.) 220: 243-256.

Mariani, J., and J. P. Changeux (1981) Ontogenesis of olivocerebellar relationships. I. Studies by intracellular recordings of the multiple innervation of Purkinje cells by climbing fibers in the developing rat cerebellum. J. Neurosci. 1: 697-702.

Martin, A. R. (1955) A further study of the statistical composition of the end-plate potential. J. Physiol. (Lond.) 130: 114-122.

McGrath, P. A., and M. R. Bennett (1979) Development of the synaptic connections between different segmental motoneurons and striated muscles in an axolotl limb. Dev. Biol. 69: 133-145.

Miyata, Y., and K. Yoshioka (1980) Selective elimination of motor nerve terminals in the rat soleus muscle during development. J. Physiol. (Lond.) 309: 631-646.
Nurcombe, V., P. A. McGrath, and M. R. Bennet (1981) Postnatal death of motor neurons during the development of brachial spinal cord of the rat. Neurosci. Lett. 27: 249-254.

Ontell, M. (1977) Neonatal muscle: An electron microscopic study. Anat. Rec. 189: 669-690.

Ontell, M., and R. F. Dunn (1978) Neonatal muscle growth: A quantitative study. Am. J. Anat. 152: 539-556.

Purves, D. (1981) Selectivity formation of synapses in the peripheral nervous system and the chemo affinity hypothesis of neural specificity. In Studies in Developmental Neurobiology, W. M. Cowen, ed., pp. 231-242, Oxford University Press, London.

Redfern, P. A. (1970) Neuromuscular transmission in new-born rats. J. Physiol. (Lond.) 209: 701-709.

Schmalbruch, H. (1982) Skeletal muscle fibers of newborn rats are coupled by gap junctions. Dev. Biol. 41 : $485-490$.

Sherrington, C. S. (1892) Notes on the arrangement of some motor fibres in the lumbo-sacral plexus. J. Physiol. (Lond.) 13: 621-772.

Thompson, W. J. (1983) Lack of segmental selectivity in elimination of synapses from soleus muscle of new-born rats. J. Physiol. (Lond.) 335: 343-352.

Wigston, D. J. (1980) Suppression of sprouted synapses in axolotl muscle by transplanted foreign nerves. J. Physiol. (Lond.) 307: 355366 .

Wigston, D. J. and J. R. Sanes (1982) Selective reinnervation of adult mammalian muscle by axons from different segmental levels. Nature 299: 464-467.

Willshaw, D. J. (1981) The establishment and the subsequent elimination of polyneuronal innervation of developing muscle: Theoretical considerations. Proc. R. Soc. Lond. Biol. 212: 233-252. 